\title{
HARMONIC SCALPEL VERSUS CONVENTIONAL TECHNIQUE IN TOTAL THYROIDECTOMY (COMPARATIVE STUDY)
}

\author{
By \\ Sawsan S. Mohamed, Mohamed O. Alfy, and Mohamed Sh. Zarad \\ Department of General Surgery, Faculty of Medicine (Girls), Al-Azhar University \\ Corresponding author: Sawsan Soliman Mohamed, Mobile: 01001464690 \\ E-mail: dr.sawsan_soliman@yahoo.com
}

\begin{abstract}
Background: Thyroid gland is a highly vascular organ. So, doing thyroidectomy requires good hemostasis even for the small blood vessels either through conventional tie technique which is time-consuming or through the use of a harmonic scalpel.

Objective: To evaluate the real benefits of the Harmonic Scalpel in total thyroidectomies when compared with conventional ligation, in terms of operative time, postoperative drainage, and complications.

Patients and methods: This randomized, prospective observational study was carried out at Al-Zahraa University Hospital, Al-Azhar University, Cairo, Egypt. Written informed consents were obtained from Seventy-six patients with benign goiter disorders who were scheduled for elective total thyroidectomy during a period from August 2019 to October 2020. Thirty eight patients were submitted to conventional thyroidectomy (group A), and thirty eight underwent thyroidectomy using a harmonic scalpel (group B).
\end{abstract}

Results: There was no statistical difference between the two groups as regards demographic data, hospital stay, recurrent laryngeal nerve injury, and hypocalcemia, but there was a statistically significant difference as regards operative time $(76.9 \pm 15.1 \mathrm{~min}$ in group A versus $89.23 \pm 17.68$ in group B) and drainage volume $(111.75 \pm 56.57 \mathrm{mls}$ in group A versus $89 \pm 16.21 \mathrm{mls}$ in group B).

Conclusion: Harmonic scalpel for total thyroidectomy is a better choice compared to the conventional tie technique as regards operative time and postoperative drainage volume.

Key Words: Total thyroidectomy; Harmonic scalpel; conventional tie technique; hemostasis.

\section{INTRODUCTION}

Thyroidectomy is a commonly performed operation in endocrine surgery. It is the most convenient therapeutic choice in the treatment of many thyroid disorders through surgical interference (Al-Dhahiry and Hameed; 2015).

Safe thyroid surgery requires meticulous hemostasis and careful control of bleeding. Whereas the thyroid has a rich blood supply, prompt hemostasis is crucial to avoid intraoperative bleeding, obtain good visualization of the surgical field, and prevent damage to structures such as parathyroid glands or laryngeal nerves. The main sources of bleeding are injured thyroid vessels and thyroid parenchymal bleeding (Revelli et al., 2016).

The conventional technique requires massive clamp-and-tie maneuvers for the small thyroid vessels and if the use of the conventional technique is time- 
consuming. On the other hand, using instruments as mono or bipolar diathermy can be unsafe because of the risk of damaging the surrounding structures caused by the adjacent thermal spread. Focus harmonic scalpel is a good solution because it is a device specifically designed for having an accurate dissection and efficient hemostasis in all the procedures realized in a narrow operating field as in thyroid surgery (Minni et al., 2016).

Harmonic scalpel allows simultaneous cutting and coagulation of vessels by using mechanical ultrasound energy at a frequency of $55.5 \mathrm{kHz}$ (Cannizzaro et al., 2014).

It has been shown that thermal injury induced by ultrasound is reduced when compared to electrocoagulation, which uses higher temperatures $(150-4008 \mathrm{C})$ (Migliore et al., 2013).

Using harmonic focus, blood vessels with a diameter until $5 \mathrm{~mm}$ did not need additional protection by ligation, and this implicates a significant decrease of total operative time as shown in our study and even a significant reduction of the use of material (sutures, clips) (Minni et al., 2016).

This prospective randomized study aimed to evaluate the real benefits of the Harmonic Scalpel in total thyroidectomies when compared with conventional ligation, in terms of operative time, postoperative drainage, length of stay, and complications.

\section{PATIENTS AND METHODS}

This randomized, prospective observational study was carried at AlZahraa University Hospital, Faculty of
Medicine for girls, Al-Azhar University, Cairo, Egypt. Written informed consents were obtained from Seventy-six patients with benign goiter disorders who were scheduled for elective total thyroidectomy after obtaining approval from the hospital ethical committee during a period from August 2019 to October 2020.

All selected patients presented with goiters which were diagnosed by clinical examination, ultrasound scan, and confirmed by histopathological examination of the biopsy taken.

All patients presented with simple nodular goiter and solitary thyroid nodule. Exclusion criteria were: Patients who refused to participate in the study, presence of preoperative vocal cord dysfunction, giant goiter, Grave's disease, retrosternal goiter, toxic goiter, and patients unfit for general anesthesia.

All patients were subjected to detailed personal data, general and local examination, Laboratory investigations (preoperative preparation and thyroid hormone levels), Radiology by ultrasound (US).

Patients were randomized into two groups according to the hemostatic technique:

Group (A): Conventional thyroidectomy group (CT), where dissection and hemostasis were performed using conventional materials (Vicryl 3-0/2-0, stitches, and monopolar or bipolar electrocautery).

Group (B): Harmonic scalpel group (HS), in which the Harmonic Focus was used. The application of ultrasound to tissues was performed during the entire procedure 
to obtain three purposes synergistically: coagulation, cutting, and cavitation.

All surgical procedures were performed under general anesthesia with endotracheal intubation. All operations were performed using a standardized capsular dissection technique through a collar incision. The lobe of the thyroid gland was progressively dissected away from strap muscles; its vascular pedicles were ligated with Vicryl $2 / 0$ suture or coagulated and divided with HS. The thyroid lobe was progressively dissected off the trachea after the recurrent laryngeal nerves and parathyroid glands were identified and dissected off the thyroid capsule. After securing hemostasis, a suction drain was routinely put in the thyroid bed as a part of the study protocol to measure the amount of blood loss during the first 48 hours.
The parameters considered in this study were operative time (time from skin incision to the end of wound closure), amount of drainage, time of positioning of drainage balloons (the drains were removed if drainage volume was less than $10 \mathrm{ml}$ in 24 hours).

\section{Statistical analysis:}

Data were collected, revised, coded, and entered into the Statistical Package for the Social Sciences (IBM SPSS) version 23 (IBM Corp., Armonk, New York, USA). The quantitative data were presented as mean, standard deviations, and ranges and were compared by independent t-test or Mann-Whitney U test Qualitative data were presented as numbers and percentages and were compared by the Chi-square test (X2) or Fisher's Exact test. P-value was considered significant at $\mathrm{p}<0.05$.

\section{RESULTS}

Seventy-six patients were included in this study, 38 patients underwent total thyroidectomy using conventional tie technique (group A) and 38 patients underwent total thyroidectomy using harmonic scalpel (group B). There was no significant difference was observed in mean age, gender, Co-morbidities, mean hospital stay, hypocalcemia, and wound seroma of either group.

Regarding the operative time of surgery was significantly shorter in the harmonic group (HS) than in the conventional technique group (CT):
$76.9 \pm 15.1 \quad \min \quad$ vs $\quad 89.23 \pm 17.68$ respectively.

Regarding drainage volume, there was a statistically significant difference between the two groups.

No significant difference for temporary RLN palsy rate was found between groups. We experienced no case of permanent RLN paralysis.

All patients who were complicated postoperatively by hypoparathyroidism recovered within 2 months, while no patient was complicated by permanent hypoparathyroidism (Table 1). 
SAWSAN S. MOHAMED et al.,

Table (1): Comparison between the two groups (Mean \pm SD)

\begin{tabular}{|c|c|c|c|}
\hline Groups & Group A (CT) & Group B (HS) & \\
\hline Parameters & No. $=38$ & No. $=38$ & P-value \\
\hline $\begin{array}{l}\text { Age (years) } \\
\text { Mean } \pm \text { SD } \\
\text { Range }\end{array}$ & $\begin{array}{c}39 \pm 11.3 \\
21-57\end{array}$ & $\begin{array}{c}39.6 \pm 10.8 \\
25-55\end{array}$ & 0.814 \\
\hline $\begin{array}{l}\text { Sex } \\
\text { Male } \\
\text { Female }\end{array}$ & $\begin{array}{c}6(15.7 \%) \\
32(84.3 \%)\end{array}$ & $\begin{array}{c}4(10.5 \%) \\
34(89.5 \%)\end{array}$ & 0.497 \\
\hline $\begin{array}{l}\text { Co-morbidities } \\
\text { HTN } \\
\text { Diabetes }\end{array}$ & $\begin{array}{c}5(13.1 \%) \\
3(7.8 \%)\end{array}$ & $\begin{array}{l}4(10.5 \%) \\
2(5.26 \%)\end{array}$ & $\begin{array}{l}0.723 \\
0.644 \\
\end{array}$ \\
\hline $\begin{array}{l}\text { Operative time (min) } \\
\text { Range } \\
\text { Mean } \pm \text { SD }\end{array}$ & $\begin{array}{c}60-140 \\
89.23 \pm 17.68\end{array}$ & $\begin{array}{c}48-120 \\
76.9 \pm 15.1\end{array}$ & 0.002 \\
\hline Drainage volume (mls) & $111.75 \pm 56.57$ & $89 \pm 16.21$ & 0.020 \\
\hline Hospital stay (days) & $2.7 \pm 0.6$ & $2.6 \pm 1$ & 0.599 \\
\hline $\begin{array}{l}\text { Recurrent laryngeal nerve } \\
\text { injury } \\
\text { Transient } \\
\text { Permanent }\end{array}$ & $\begin{array}{l}2(5.2 \%) \\
0(0.0 \%)\end{array}$ & $\begin{array}{l}2(5.2 \%) \\
0(0.0 \%)\end{array}$ & $\begin{array}{c}1.000 \\
\text { NA }\end{array}$ \\
\hline $\begin{array}{l}\text { Hypocalcemia } \\
\text { Transient } \\
\text { Permanent }\end{array}$ & $\begin{array}{c}5(13.1 \%) \\
0(0.0 \%)\end{array}$ & $\begin{array}{l}3(7.9 \%) \\
0(0.0 \%)\end{array}$ & $\begin{array}{c}0.455 \\
\text { NA }\end{array}$ \\
\hline Wound seroma & $1(2.6 \%)$ & $0(0.0 \%)$ & 0.314 \\
\hline Reoperation & $0(0.0 \%)$ & $0(0.0 \%)$ & NA \\
\hline
\end{tabular}

\section{DISCUSSION}

This study compared between harmonic scalpel and conventional tie technique in total thyroidectomy in which there was no significant difference was observed in mean age, gender, comorbidities, mean hospital stay, hypocalcemia, and wound seroma of either group, but there was a statistically significant difference between the two groups, as regarding operative time.

Using Harmonic focus ultrasonic scalpel, there was a significantly decreased amount of drainage after surgery, and this was confirmed by numerous randomized trials that reported an important intra-operative blood loss reduction in addition to a post-operative drainage decrease (Duan et al., 2013).
It is of fundamental importance to properly use this device in the vicinity of extremely delicate structures such as the RLN. Though Carlander et al. (2012) showed that a Harmonic scalpel (HS) causes less trauma to adjacent nerve fibers than bipolar electro-surgery, also HS may cause nerve injury at close distances (Revelli et al., 2016).

HS seals vessels up to $5 \mathrm{~mm}$ in diameter offering a precise and accurate surgical dissection as in the thyroid surgery with a great saving of operative times. Its lateral thermal damage is limited up to $2 \mathrm{~mm}$ beyond the tissue grasped within the forceps of the device (Cannizzaro et al., 2016). 
The use of advanced vessel sealing devices has been recommended in several studies regarding thyroid surgery, reporting the efficacy of hemostasis, reduction of operative time, postoperative pain, transient hypocalcemia, use of hemostatic agents, and cost (Bove et al., 2012 and Materazzi et al., 2013).

Luo et al. (2017) performed a metaanalysis that compared harmonic scalpel and LigaSure hemostatic devices with the conventional clamp-and-tie technique of hemostasis in goiter- or cancer-related thyroid surgery. They found some differences in clinical outcomes between the three hemostatic modalities. Compared with the conventional hemostasis, there was a significant reduction in operation time with both the harmonic scalpel and LigaSure.

Contin et al. (2013) and Garas et al. (2013) performed a pair-wise metaanalysis and a network meta-analysis to compare the efficacy of ultrasonic harmonic scalpel, LigaSure, and the conventional hemostatic procedures in thyroid surgery. Both studies found that harmonic scalpel and LigaSure were associated with shorter operation time for thyroidectomy than the conventional hemostasis, and that harmonic scalpel was associated with the shortest operative time.

The reduction in operative times, as is true with any surgical procedure, typically will reduce the risk of surgical- site infection and may lead to faster patient recovery time (Elfenbein et al., 2014).

Sutureless thyroidectomy not only reduces the operative time, but also reduces the iatrogenic complications like neurovascular injuries around the thyroid gland (Cannizzaro et al., 2016).

Chang et al. (2011) observed no statistical difference in postoperative complications, but the mean of operative time was significantly lower in the sutureless groups.

Lang et al. (2013) in a systematic review of the literature observed a reduction of volume of blood loss and operating time in the HS group compared to the LigaSure group.

Focus Harmonic Scalpel has certain advantages over conventional Haemostasis in protecting parathyroid glands, reducing the incidence of transient hypoparathyroidism and hypocalcemia in thyroid surgery, especially for patients with thyroid cancer (Xu et al., 2019).

Ruggiero et al. (2018) found that the use of an ultrasonic scalpel is effective both in the hemostasis of all vessels and in the dissection of tissues near the course of the laryngeal nerves, respecting the safety margins, and Berry's and Gruber's ligaments. Moreover, this device has a lateral thermal spread of $2 \mathrm{~mm}$, so that this is a remarkable advantage in comparison to high temperature achieved by mono- or bipolar scalpel near the noble structures such as recurrent laryngeal nerves and parathyroid glands.

\section{CONCLUSION}

The use of a Harmonic scalpel during thyroidectomy reduced the operative time and postoperative blood loss.

Conflict of Interest: No conflict of interest was declared by the authors. 
Financial Disclosure: The authors declared that this study has received no financial support.

\section{REFERENCES}

1. Al-Dhahiry JK. and Hameed HM. (2015): Total thyroidectomy: Conventional Suture Ligation technique versus sutureless techniques using Harmonic Scalpel or Maxium. Annals of Medicine and Surgery,5: 29-34.

2. Bove A., Papanikolaou I., Bongarzoni G., Mattei P., Markogiannakis H., Chatzipetrou M., D'Addetta V., Di Renzo R., Fiordaliso $M$. and Corbellini $L$. (2012): Thyroid surgery with harmonic focus, ligasure precise and conventional technique: a retrospective case-matched study. Hippokratia, 16(2), 154-59.

3. Cannizzaro M., Borzì L., Bianco SL., Okatyeva V., Cavallaro A., and Buffone A. (2016): Comparison between Focus Harmonic scalpel and other hemostatic techniques in open thyroidectomy: A systematic review and meta-analysis. Head \& Neck, 38(10):1571-1578.

4. Carlander J., Koch C., Brudin L., Nordborg C., Gimm O., and Johansson K. (2012): Heat production, nerve function, and morphology following nerve close dissection with surgical instruments. World Journal of Surgery, 36(6): 1361-1367.

5. Chang LY., O'Neill C., Suliburk J., Sidhu S., Delbridge L. and Sywak M. (2011): Sutureless total thyroidectomy: a safe and cost- effective alternative. ANZ Journal of Surgery, 81(7-8): 510-514.

6. Contin P., Gooben K., Grummich K., Jensen K., Schmitz-Winnenthal H., Büchler MW. and Diener MK. (2013): Energized vessel sealing systems versus conventional hemostasis techniques in thyroid surgery--the ENERCON systematic review and network meta-analysis. Langenbeck's Archives of Surgery, 398(8): 1039-56.

7. Duan YF., Xue W., Zhu F., and Sun DL. (2013): FOCUS harmonic scalpel compared to conventional hemostasis in open total thyroidectomy - a prospective randomized study. Journal of Otolaryngology-Head \& Neck Surgery, 42(1), 62.

8. Elfenbein DM., Schneider DF. and Chen H. (2014): Surgical site infection after thyroidectomy: a rare but significant complication. J Surg Res., 190(1):170-76.

9. Garas G., Okabayashi K., Ashrafian H., Shetty K., Palazzo F., Tolley N., Darzi A., Athanasiou T. and Zacharakis E. (2013): Which hemostatic device in thyroid surgery? A network meta-analysis of surgical technologies. Thyroid: official journal of the American Thyroid Association, 23(9): 1138-1150.

10. Lang BH., Ng SH., Lau LL., Cowling BJ. and Wong KP. (2013): A systematic review and meta-analysis comparing the efficacy and surgical outcomes of total thyroidectomy between harmonic scalpel versus ligasure. Annals of Surgical Oncology, 20(6): 1918-26. 


\section{HARMONIC SCALPEL VERSUS CONVENTIONAL TECHNIQUE IN...}

11. Luo Y., Li X. and Dong J. (2017): A comparison of surgical outcomes and complications between hemostatic devices for thyroid surgery: a network meta-analysis. Eur Arch Otorhinolaryngol. (274): 1269-78.

12. Materazzi G., Caravaglios G. and Matteucci V. (2013): The impact of the Harmonic focus on complications in thyroid surgery: a prospective multicenter study. Updates in Surgery, 65(4):295-299.

13. Migliore M., Alongi G., Rampello L. and Astuto M. (2013): Video-assisted transcervical thymectomy: a minimally invasive approach to treat nonthymomatous myasthenia gravis. Ann Ital Chir., 83:667-70.

14. Minni A., Rosati D., Cavaliere C., De Carlo A., Illuminati G., Scarano Catanzaro V. and Bodoni M. (2016): Study on the use of focus harmonic scalpel in thyroidectomies: is it useful also in preserving voice function? European Review for Medical and
Pharmacological Sciences, 20(17): 3544-3551.

15. Revelli L., Damiani G., Bianchi C B., Vanella S., Ricciardi W., Raffaelli M. and Lombardi C P. (2016): Complications in thyroid surgery. Harmonic Scalpel, Harmonic Focus versus Conventional Hemostasis: A meta-analysis. International journal of surgery (London, England), 28 Suppl (1): S22-S32.

16. Ruggiero, R., Docimo, G., Bosco, A., Lanza Volpe, M., Terracciano, G., Gubitosi, A., and Docimo, L. (2018): Update on sutureless thyroidectomy. Il Giornale Di chirurgia, 39(1): 45-50.

17. Xu SQ., Ma Y., Su HW., Cheng JF. and Zhou, Y. X. (2019): Comparison Of The Effects Of Focus Harmonic Scalpel And Conventional Haemostasis On Parathyroid Function In Thyroid Surgery. Journal of Ayub Medical College, Abbottabad: JAMC, 31(4): 481-484. 
المبضع التو افقي مقابل التقنية التقلبدية في إستئصال الغدة

الدر قبة الكلي (در اسة مقارنة) معانة

سوسن سليمان محمد سليمان، محمدعمر محمد الالفى، محمد شحاته زرد

قسم الجراحة العامة، كلية طب بنات الازهر

E-mail: dr.sawsan_soliman@yahoo.com

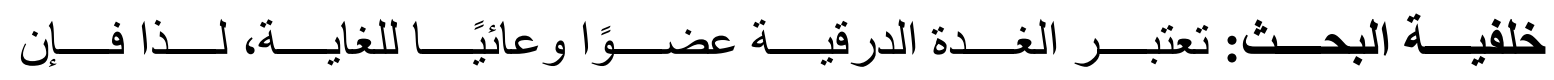

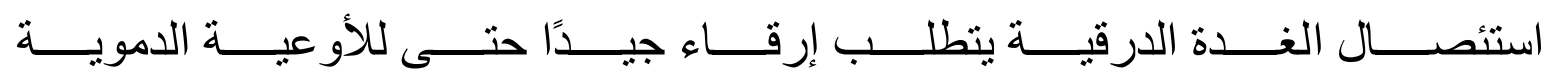

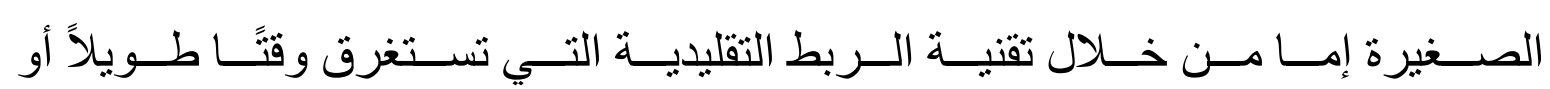
من خلال استخدام مشرط متناسق.

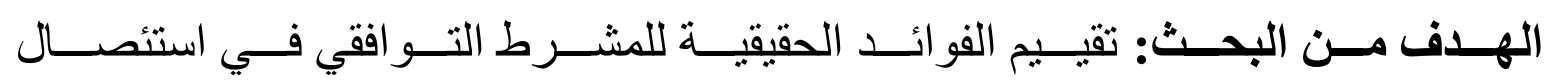

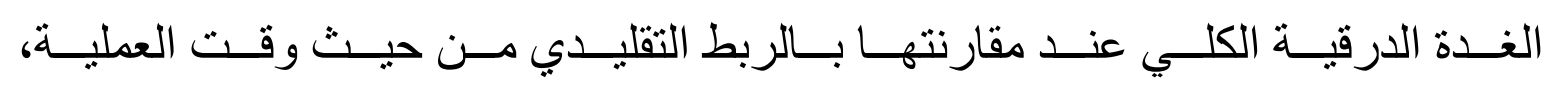
و الصرف بعد الجر احة، والمضاعفات.

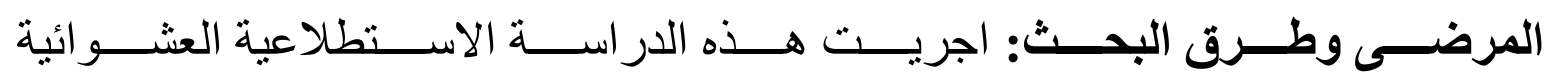

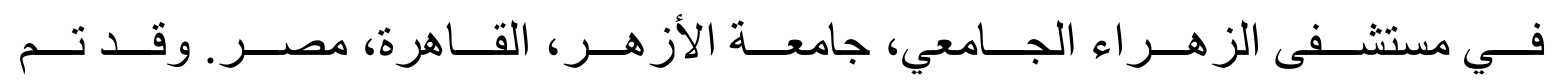

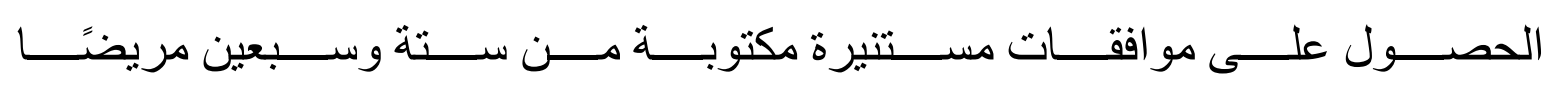

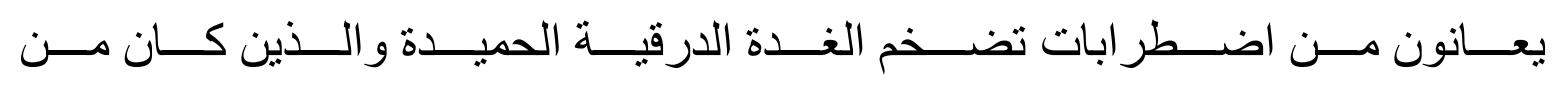

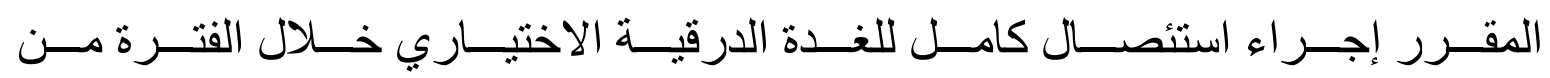

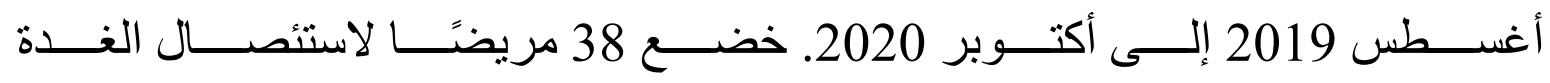

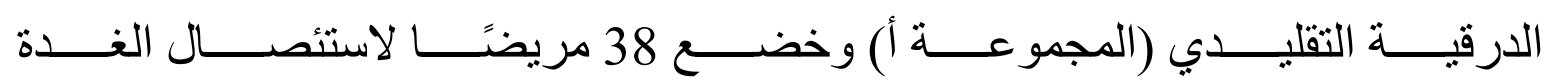
الدرقية باستخدام مشرط متناست.

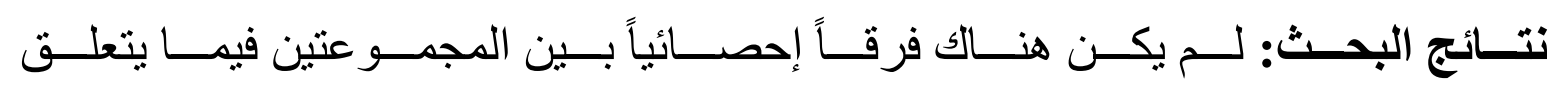

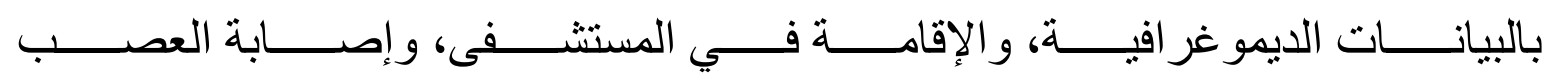

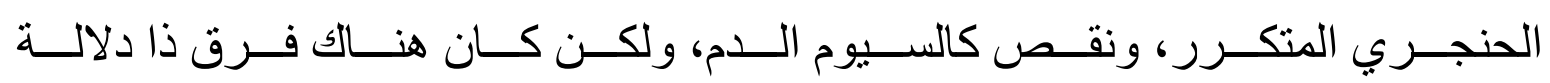


HARMONIC SCALPEL VERSUS CONVENTIONAL TECHNIQUE IN...

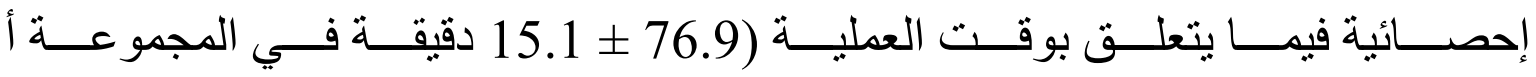

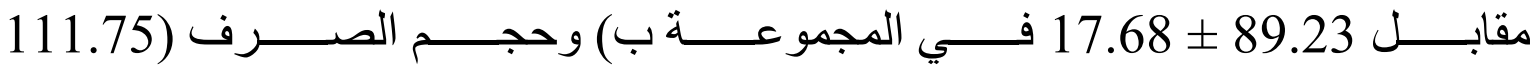

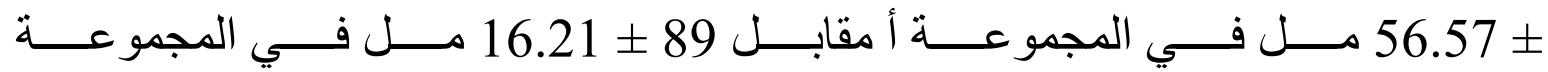
ب).

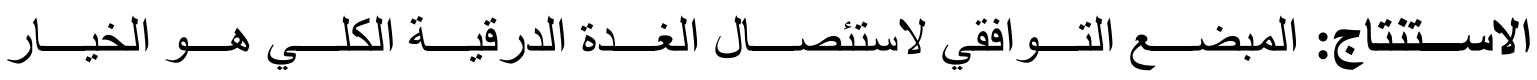

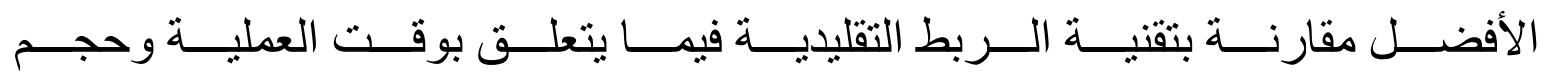
التصريف بعد الجر احة.

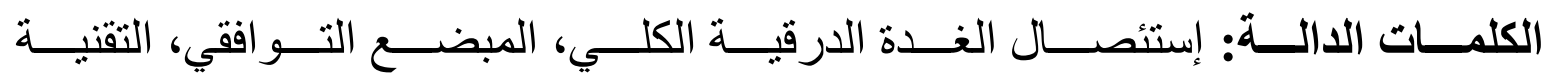
التقليدية، التخثر. 